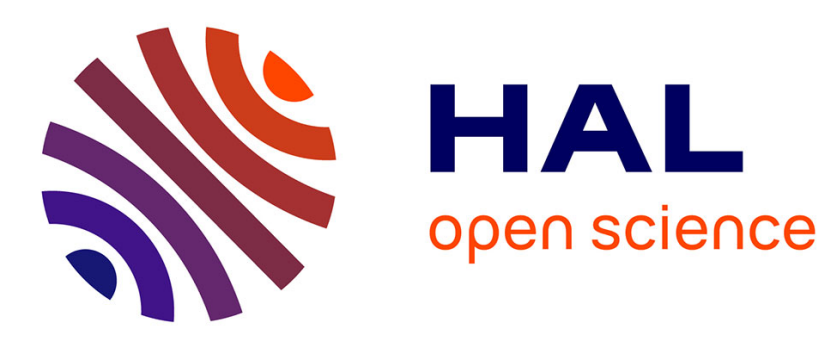

\title{
Strong explosion near a parallelepipedic structure
}

\author{
Sophie Trelat, Isabelle Sochet, B. Autrusson, K. Cheval, O. Loiseau
}

\section{To cite this version:}

Sophie Trelat, Isabelle Sochet, B. Autrusson, K. Cheval, O. Loiseau. Strong explosion near a parallelepipedic structure. Journal Shock Waves, 2007, 16 (4-5), pp.349-357. 10.1007/s00193-006-0069-3 . hal-00647799

\section{HAL Id: hal-00647799 \\ https://hal.science/hal-00647799}

Submitted on 2 Dec 2011

HAL is a multi-disciplinary open access archive for the deposit and dissemination of scientific research documents, whether they are published or not. The documents may come from teaching and research institutions in France or abroad, or from public or private research centers.
L'archive ouverte pluridisciplinaire HAL, est destinée au dépôt et à la diffusion de documents scientifiques de niveau recherche, publiés ou non, émanant des établissements d'enseignement et de recherche français ou étrangers, des laboratoires publics ou privés. 


\title{
Original article
}

\section{Strong explosion near a parallelepipedic structure}

\author{
S. Trélat ${ }^{1}$, I. Sochet ${ }^{1}$, B. Autrusson ${ }^{2}$, O. Loiseau ${ }^{2}$, K. Cheval ${ }^{2}$ \\ 1 Laboratoire Energétique Explosions Structures, Ecole Nationale Supérieure d'Ingénieurs de Bourges, 10 bvd Lahitolle 18020 \\ Bourges cedex, France e-mail: isabelle.sochet@ensi-bourges.fr \\ 2 Institut de Radioprotection et de Sûreté Nucléaire, DEND/SATE, BP 17, 92262 Fontenay-aux-Roses Cedex, France
}

The date of receipt and acceptance will be inserted by the editor

\begin{abstract}
The purpose of this paper is to report the blast loading characteristics resulting from the detonation of a stoichiometric propane-oxygen mixture, and to validate the approach which relies on simulating TNT explosions at large scale by small scale experiments of gaseous explosions. Several dimensionless correlations are obtained from experimental data. These relationships allow determination of the parameters of a blast wave interacting with a structure as a function of the positions of the explosive charge and the structure. Simulations carried out with the Autodyn code show good correlation with experimental results. The Hopkinson law is suggested to predict the blast wave's parameters at large scale on the basis of small scale experiments and simulations.
\end{abstract}

Key words gaseous detonation, shock wave, interaction on a structure, TNT equivalent, blast wave

\section{Introduction}

In an industrial safety context, it is important to know the blast characteristics whenever an explosion occurs near a building. The problem arises from the impact of an overpressure wave on structures that may be catastroph under certain conditions. Overpressure histories including the positive peak overpressure, the arrival time and the positive phase duration, are dependent on several parameters such as the charge type (gaseous or solid charge), the volume, and the location of the explosive charge.

Several experiments have been conducted to define the properties of spherical blast waves in free air and reflected waves on surfaces. The charge can be defined by a TNT charge [8] [2] [6], or by a gaseous mixtures [4] [5] were studied. TThe TNT equivalency method of explosive sources makes it possible to express the energy release resulting from the detonation of a gas mixture in terms of TNT equivalent energy [6].

The first objective of this study is to obtain experimental data on the blast loading characteristics resulting from the detonation of a stoichiometric propane-oxygen mixture near a parallelepipedic building versus the distance between the explosive charge and the building, and versus the angle of incidence of the shock wave on the structure. The second objective is to validate the approach which relies on simulating TNT explosions at large scale by small scale experiments of gaseous explosions. The third objective is to validate the threedimensional computational fluid dynamics (CFD) code Autodyn against experimental data in the free field and over obstructed terrain.

\section{Experimental setup}

The experimental investigation uses small-scale experiments (Fig. 1). The detonating gas (stoichiometric propaneoxygen mixture) is confined in a soap bubble (radius $0.03 \leq R_{0} \leq 0.07 \mathrm{~m}$ ) on a large plane surface (length $1.80 \mathrm{~m}$, width $1.20 \mathrm{~m}$ ). The detonation is ignited by an exploding wire at the center of the hemispherical bubble. This exploding wire (length $0.01 \mathrm{~m}$ and diameter $1.2 \cdot 10^{-4} \mathrm{~m}$ ) made of copper and zinc delivers an electrical pulse with a charge voltage equal to 7000 Volts. The capacitance of the ignition system is $8.14 \mu \mathrm{F}$. The pressure gauges (Kistler 603B) are distributed on the plane surface in front of the soap bubble with a radial distance $r$ from the center of explosion Es $(0.07 \leq r \leq 0.7 \mathrm{~m})$ (Fig. 3). This experimental setup allows observation of the shock wave propagating in the free field (Fig. 3); it is then possible to study the pressure wave evolution in a flow field which is obstructed by a parallelepipedic PVC structure (Fig. 1). Its length, width and height are $0.40 \mathrm{~m}, 0.18 \mathrm{~m}$ and $0.14 \mathrm{~m}$ respectively (cf. Fig. 2). As the shock wave impacts the structure on a plane surface (configurations 1 and 2 in Fig. 4. 5), the resulting 


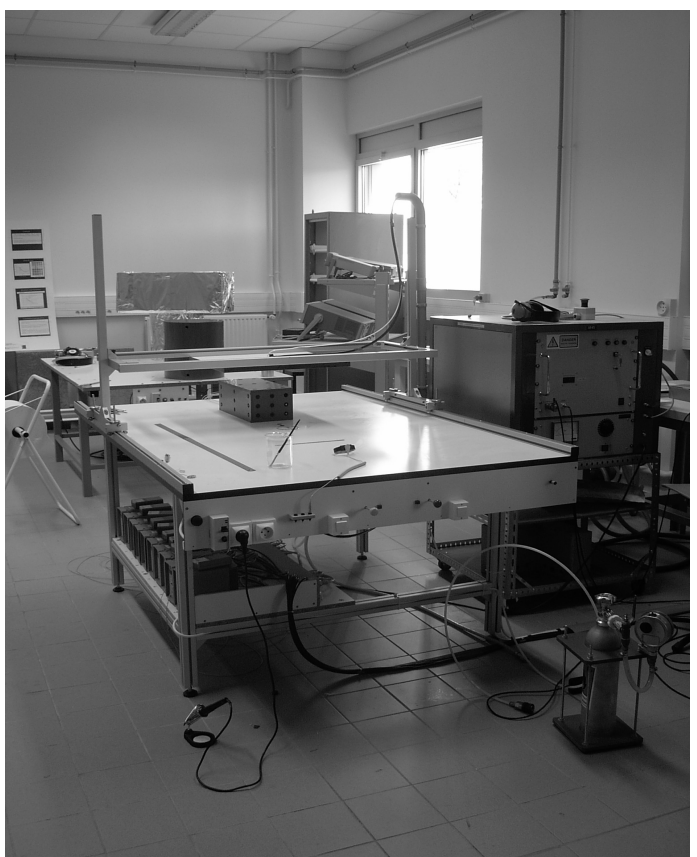

Fig. 1 The experimental setup

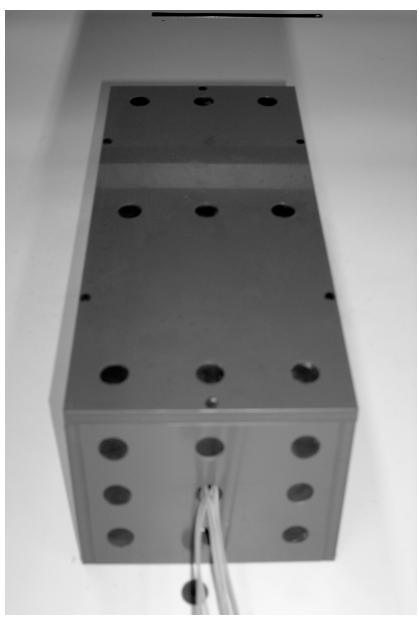

Fig. 2 The PVC structure with the gauges

reflection is a normal ; in the case of the configuration $3\left(\theta=30-45\right.$ or $60^{\circ}$, Fig. 6$)$, the reflected wave is an oblique shock wave and the situation is comparable with a shock wave impacting a double wedge.

The different positions of the center of explosion on the surface plane are given in Fig. 3, 4, 5 and 6. Figure 3 shows the free field configuration that enables measurement of incident pressures. Figures 4 and 5 show configuration 1 and configuration 2, which measure normal reflected pressures. Figure 6 concerns oblique reflections: an angle $\theta$ is defined so that the straight line $(\Delta)$ and the small face of the parallelepipedic structure cross at angle $\theta$.

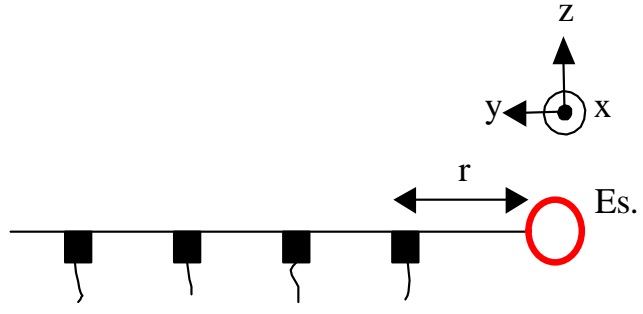

Fig. 3 Free field configuration.
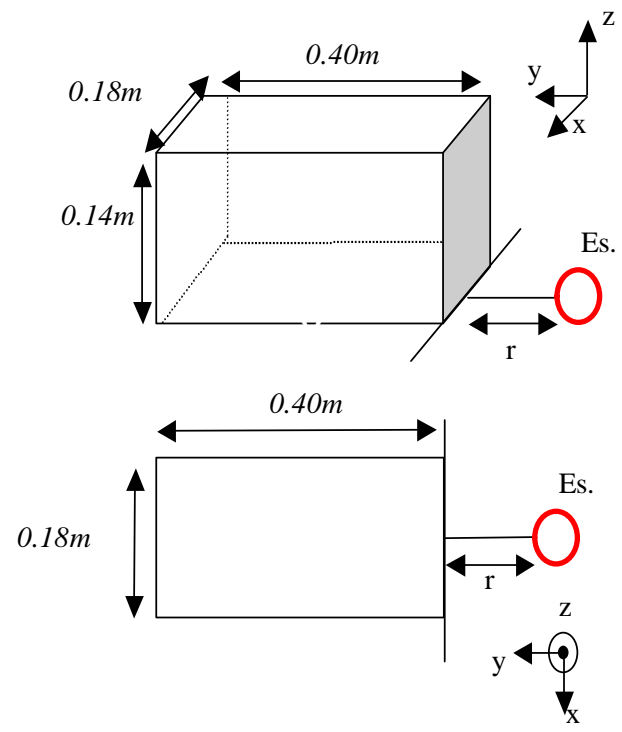

Fig. 4 The parallelepipedic structure and the different positions of the explosive source: configuration $1.3 \mathrm{D}$ view and top view of the experimental setup.

\section{TNT equivalency}

When it is possible, the experimental data are compared (Fig. 7) with the similar TNT curves ([10] [2]. ). An energy equivalency coefficient $\alpha$ can be deduced by comparison. The positive phases of the incident, reflected pressures and impulses are equivalent for TNT (energy $\left.E_{T N T}\right)$ and gaseous charges $\left(E_{\text {gas }}\right)$ if the energies are related by $E_{\text {gas }}=\alpha \cdot E_{T N T}$.

Indeed, if one slides the overpressure curve of a gaseous explosion on the TNT plot from Baker along the axis of the reduced distance on the abscissa, a ratio of $77 \%$ is obtained. A similar step can be carried out with reduced impulses by sliding the gas curve on the TNT plot along the diagonal. A ratio of $72 \%$ is obtained, which is comparable to the value obtained for overpressures. In the same way, a ratio of $79 \%$ is deduced for the positive phase duration. The difference between these ratios can be explained by the shape of the pressure signal, which is not the same if the blast wave is generated by a gaseous detonation or by a TNT detonation. Nevertheless, we 


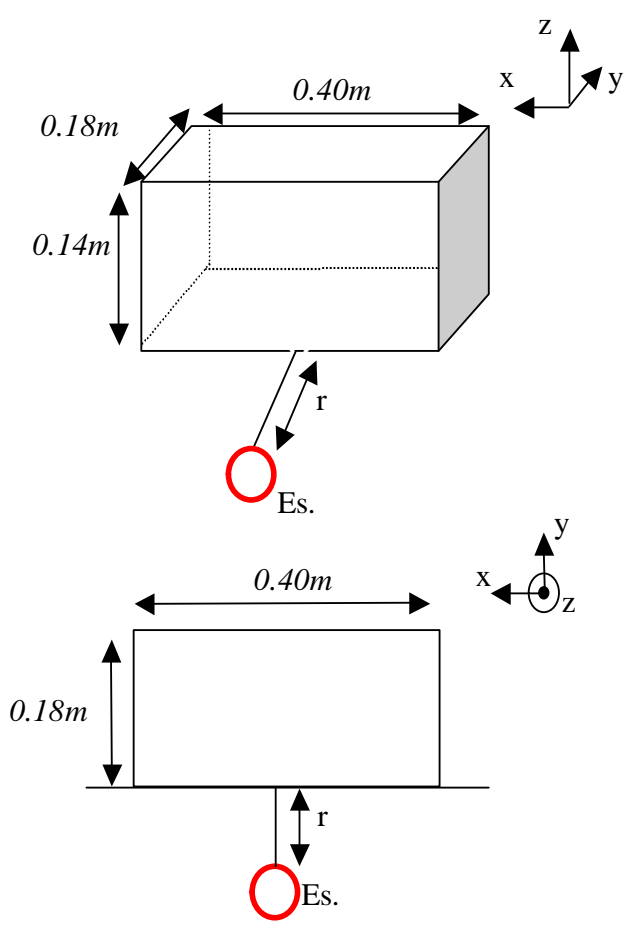

Fig. 5 The parallelepipedic structure and the different positions of the explosive source: configuration 2. 3D view and top view of the experimental setup.

assume, in the following results, a unique average ratio of $76 \%$.

Positive incident, reflected pressures and impulses are equivalent for TNT (energy $E_{T N T}$ ) and gaseous charges $\left(E_{\text {gas }}\right)$ if $\lambda=\left(\frac{R}{E^{\frac{1}{3}}}\right)_{T N T}=1$ and $\lambda=\left(\frac{R}{E^{\frac{1}{3}}}\right)_{\text {gas }}=0.76$ which leads to: $\frac{R_{\text {gas }}}{R_{T N T}}=\frac{0.76}{1}\left(\frac{E_{\text {gas }}}{E_{T N T}}\right)^{\frac{1}{3}}$. The radial distance will be the same if $E_{g a s}=2.3 \cdot E_{T N T}$.

For the mixture considered: $\mathrm{C}_{3} \mathrm{H}_{8}+5 \mathrm{O}_{2}$, the enthalpy of the reaction is equal to $\Delta H_{R}^{*}=2.044{\mathrm{MJ} . \mathrm{mol}^{-1} \text { and }}^{*}$ the chemical energy $E_{v, \text { gas }}$ released per unit volume is expressed by $E_{v, \text { gas }}=15.2 \mathrm{MJ}_{\mathrm{J}} \mathrm{m}^{-3}$. Then, by making use of the formula $E_{\text {gas }}=E_{v, \text { gas }} \cdot \frac{4}{3} \pi R_{0}^{3}$ where $R_{0}$ is the bubble radius, the energy released by different bubbles is calculated (Table 1.)

Table1. Chemical energy released $E_{\text {gas }}$

in a spherical charge.

\begin{tabular}{|c|c|c|c|c|c|}
\hline \multicolumn{5}{|c|}{$\mathrm{C}_{3} \mathrm{H}_{8}+5 \mathrm{O}_{2}->3 \mathrm{CO}_{2}+4 \mathrm{H}_{2} \mathrm{O}$} \\
\hline \multicolumn{4}{|c|}{$\Delta \mathrm{H}_{R}^{*}=2.044 \mathrm{MJ}$} & \multicolumn{2}{c|}{$E_{v, \text { gas }}=15.2 \mathrm{MJ}^{-3}$} \\
\hline$R_{o}(m)$ & 0.03 & 0.04 & 0.05 & 0.06 & 0.07 \\
\hline$E_{\text {gas }}(k J)$ & 1.72 & 4.07 & 7.96 & 13.75 & 21.84 \\
\hline
\end{tabular}

Finally, knowing the TNT energy release $E_{T N T, m}=$ $4690 \mathrm{~kJ} / \mathrm{kg}$ [7], the TNT equivalent mass $m_{T N T}$ is determined as function of the radius of the charge $R_{0}(\mathrm{~m})$

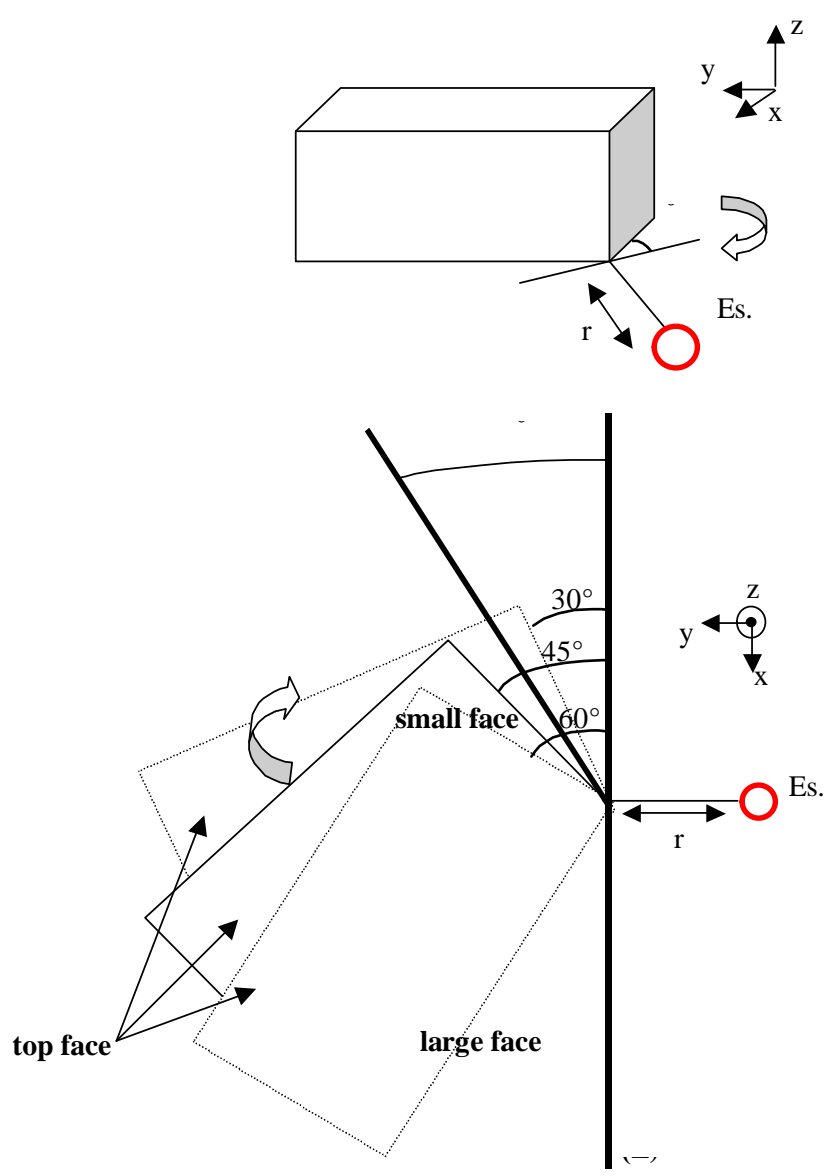

Fig. 6 The parallelepipedic structure and the different positions of the explosive source: configuration 3. 3D view and top view of the experimental setup.

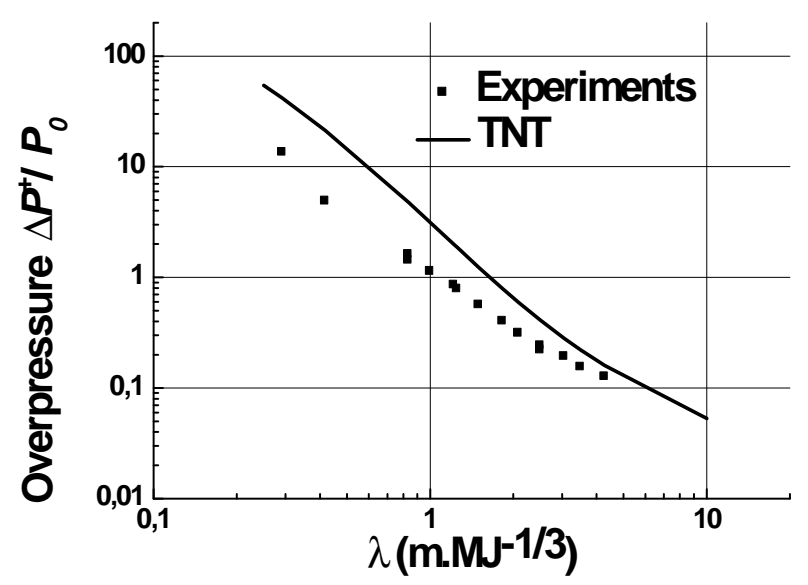

Fig. 7 Incident positive overpressure as a function of reduced radial distance $\lambda\left(\mathrm{m} . \mathrm{MJ}^{\frac{-1}{3}}\right)$ 
and is equal to:

$$
m_{T N T}=5.9 \cdot R_{0}^{3}
$$

It is interesting to compare this value of the energy equivalency coefficient with the different values deduced by Brossard ([3]) from the incident pressure measurements and the reflected pressure measurements, respectively, 5 and 2 . However, in our study, this energy equivalency coefficient $\alpha=2.3$ remains the same for the incident pressure measurements and the reflected pressure measurements. In the paperby Brossard ([3]), numerous experimental results for blast waves generated by spherical and hemispherical unconfined gaseous detonations are presented. They concern different mixtures of hydrocarbons with oxygen or air at various dilutions over a large range of volume $\left(5.2 \cdot 10^{-4}\right.$ to $\left.1.45 \cdot 10^{4} \mathrm{~m}^{3}\right)$. The detonation of air-hydrocarbon mixtures was initiated by small charges of solid explosive located at the center of symmetry either at ground level or at altitude. The different experimental configurations described in Brossard's paper may explain the two different values of the energy equivalency coefficient, in comparison with our unique value $\alpha=2.3$.

Nevertheless, we would like to emphasize the difficulty in evaluating precisely the chemical energy release $E_{\text {gas }}$ included in the spherical charge. Because the products are still hot after expanding to atmospheric pressure, only a certain fraction of the heat of combustion goes into producing the blast wave. This effect is more pronounced for fuel-air than fuel-oxygen mixtures, which might explain the differences in the equivalency coefficient $\alpha$. We have decided to use the wide approach based on the enthalpy of reaction described just above.

\section{Modelling}

The code used in this study is Autodyn [1]. Autodyn-2D and $3 \mathrm{D}$ are two and three-dimensional general-purpose finite volume, finite difference and finite element based hydrocodes that have been developed over many years to allow the efficient solution of a wide range of impact penetration and blast problems.

Autodyn models the detonation of a solid charge (cf Fig. 8 and 9). Simulations enable one to achieve gas detonations at very small and large scales, which can not be reached by means of experiments. Consequently, to perform the numerical analyses of the conducted experiments, the energy release E resulting from the detonation of the propane-oxygen mixture is expressed in terms of TNT equivalent energy.

As the energy equivalency coefficient 2.3 has been determined, it is now possible to simulate the explosion of a gaseous mixture by a TNT charge. Indeed, the equivalent released mass of TNT produces the same pressure levels as the gaseous explosive charge. For example, for the $0.06-\mathrm{m}$ radius hemisphere which confines the mixture

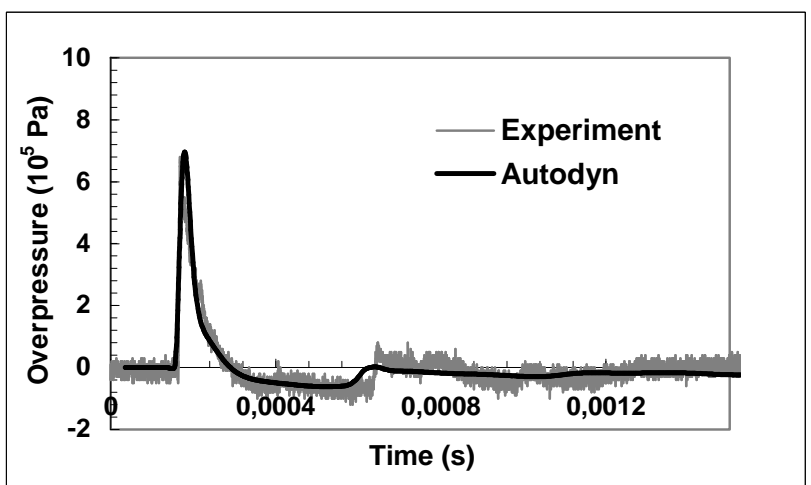

Fig. 8 Normal reflected pressure wave profile (gauge located at the center of the face, $R_{0}=0.06 \mathrm{~m}, r=0.15 \mathrm{~m}$, small scale)

within the stoichiometric composition, the TNT equivalent mass (4) is approximately equal to $1.3 \mathrm{~g}$.

The materials used in the study are AIR and TNT. Their characteristics are retrieved from the standard Autodyn library. The air is modeled by the ideal gas equation of state and the TNT material by the JWL state equation. The conducted analyses make use of Euler standard or Euler FCT solvers. Numerical analyses are undertaken in two stages. Firstly, to achieve acceptable levels of accuracy and to avoid a high number of cells required to discretise the three-dimensional model, the initial phases of the blast wave propagation are calculated one-dimensionally, as shown in this picture. Afterwards, due to the oblique wave reflection, the flow becomes multi-dimensional. Therefore, to maintain a continuous process, the solution of the one-dimensional model is saved. The second stage of the modeling procedure is composed of the "remap" operation, which transposes the final states of the cells of the one-dimensional model to the new, three-dimensional model. Such an action initiates the three-dimensional model and allows the analysis to be continued with or without the structure. The size of one-dimensional cells is $6 \cdot 10^{-5} \mathrm{~m}$ and the size of three-dimensional brick elements is $5 \cdot 10^{-3} \times 5 \cdot 10^{-3} \times$ $5 \cdot 10^{-3} \mathrm{~m}$ at small scale.

The Autodyn results are well-correlated to relevant experimental measurements (Fig. 8).

We use Hopkinson scaling laws (Fig. 10) to predict the properties of blast waves from large scale explosions. An observer located at a distance $r$ from the center of an explosive charge of characteristic dimension $d$ and of total energy $E$ will be subjected to a blast wave with amplitude $\Delta P$, duration $t$ and impulse $I$. The Hopkinson scaling law states that an observer stationed at a distance $k r$ from the center of a similar explosive source of characteristic dimension $k d$ and of total energy $k^{3} E$ detonated in the same atmosphere will feel a blast wave of "similar" form with amplitude $\Delta P$, duration $k t$ and impulse $k I$. 


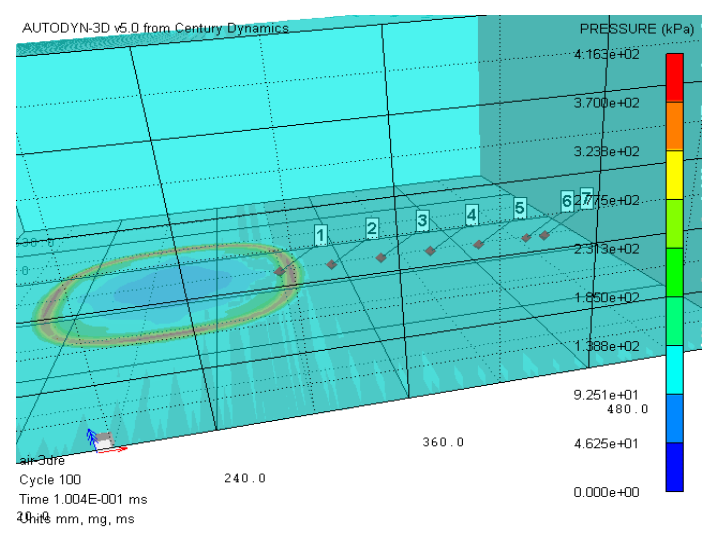

(a) in free field

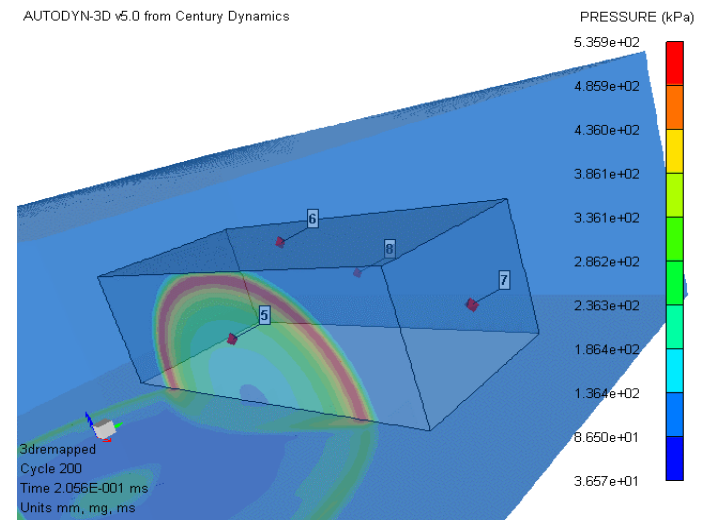

(b) configuration 2: with obstacle, normal reflection

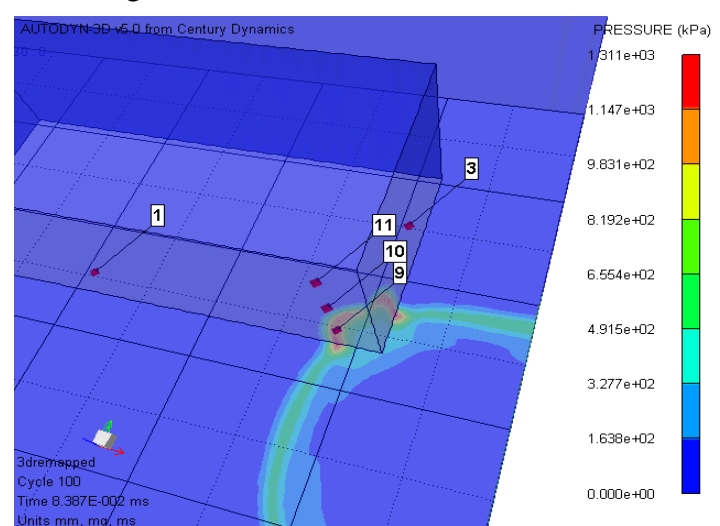

(c) configuration 3: with obstacle, oblique reflection $\left(\theta=45^{\circ}\right)$

Fig. 9 Last stages of pressure wave development in threedimensions and some gauge locations (small scale), $R_{0}=0.6$ $\mathrm{m}$, (b) (c) $r=0.1 \mathrm{~m}$

\section{Results expressed at ground level as function of radial reduced distance $\lambda\left(\mathrm{m} . \mathrm{MJ}^{1 / 3}\right)$}

An energy equivalency has been previously deduced by comparison. The positive phases of the incident, reflected pressures and impulses are equivalent for TNT (energy $\left.E_{T N T}\right)$ and gaseous charges $\left(E_{\text {gas }}\right)$ if the energies are related by $E_{g a s}=2.3 \cdot E_{T N T}$. In this section, we present the

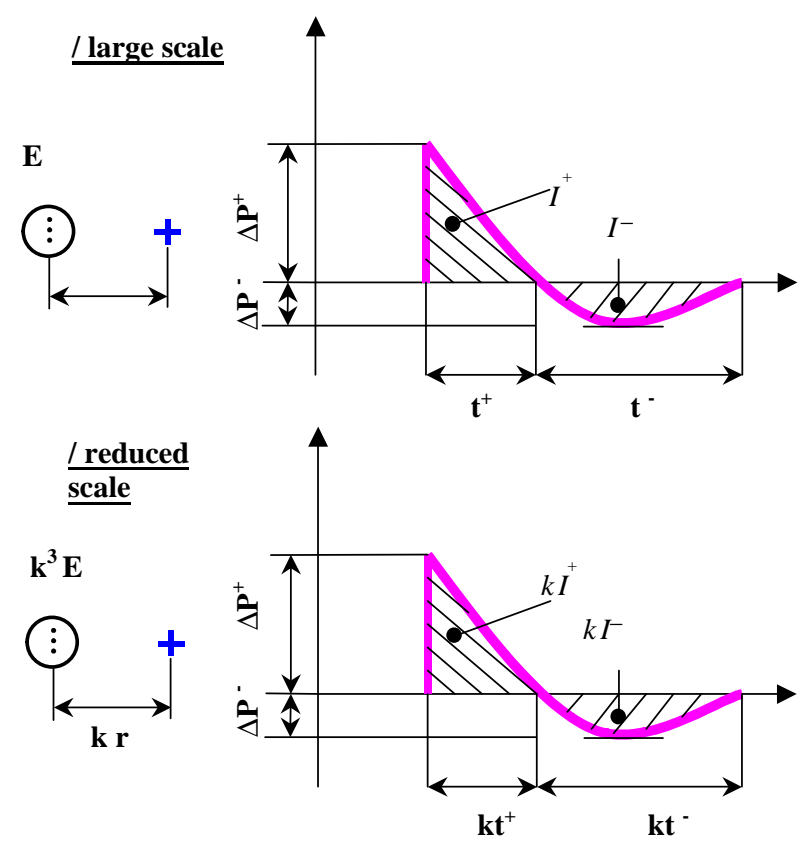

Fig. 10 Hopkinson scaling law ([8])

overpressure results (Fig. 11. 12. 13.) versus the radial reduced distance $\lambda$. Nevertheless, the other characteristics of a pressure wave (positive impulse and time duration) have been correlated as a function of $\lambda$ with the same energy equivalency. (cf Table1). Pressure signals measured on the plane surface in front of the gaseous charge are incident pressures (Fig. 3) and those measured on the structure (transducers located on the front face of the structure with respect to the explosive charge) are reflected pressures (Fig 4, 5, 6 and Fig. 17). We also show on these curves similar results from different authors ([4] [7] [5]) so that we can compare them with our results. In his paper, GE Fairlie ([7]) presents experimental tests and simulations of the channeling of a blast wave down a street type geometry (Fig. 15): a $13 \mathrm{~g}$ TNT equivalent charge (10 times higher than our equivalent charge) is detonated at the center of this street geometry (the streets cross at right angles, so it is the same geometrical configuration as our configuration 3 with $\theta=45^{\circ}$ ), so that we can compare his results with our results (Fig. 14). There is however considerable spread between the experimental results given by Fairlie ([7])(Fig. 14): there are wide variations in the three experimental pressure time histories; indeed, three sets of experimental results are shown as each experimental configuration was repeated three times.

In Brossard's paper ([4]), the purpose is to supply several useful curves as a function of the single parameter $\left(\lambda=\frac{R}{E^{\frac{1}{3}}}\right)$ in the range $0.5-20$, that are similar to those established for TNT: these results concern the detonation of gaseous charges and take into account both the 


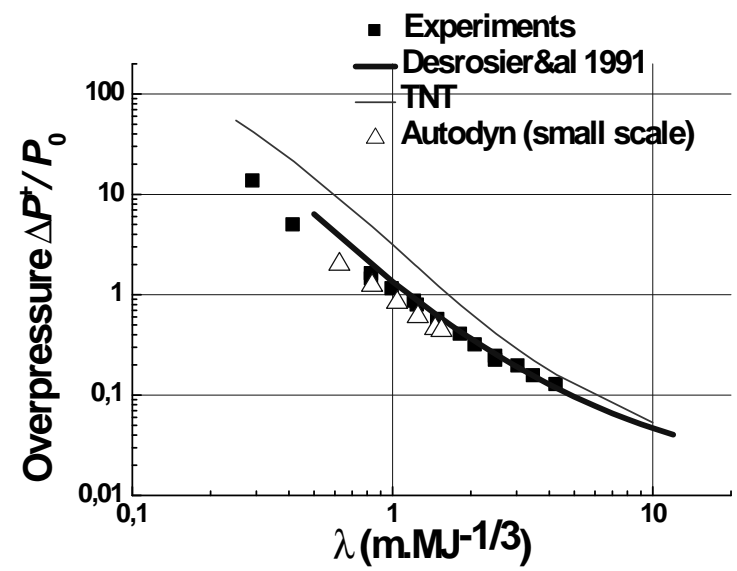

Fig. 11 Blast loadings for experimental and numerical models: positive incident overpressure as a function of reduced radial distance $\lambda$ (the pressure transducers are located at ground level, Fig. 3.)

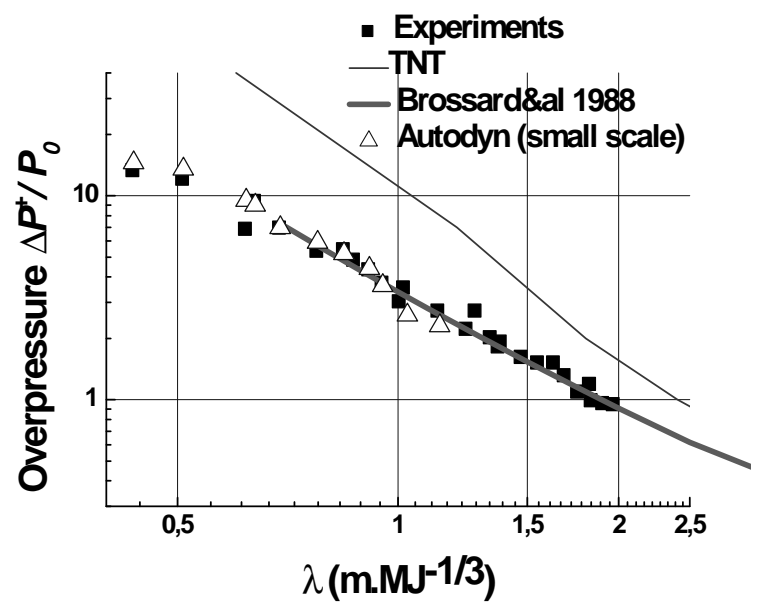

Fig. 12 Blast loadings for experimental and numerical models: positive reflected overpressure (configuration 1, Fig. 4) as a function of reduced radial distance $\lambda$

positive and the negative phases of the pressure signal of the reflected wave on a plane surface. This pressure signal characterizes the dynamic load imposed by the blast wave. The pressure wave is generated by a hemispherical charge (radius $0.025 \leq R_{0} \leq 0.12 \mathrm{~m}$ ) of stoichiometric propane-oxygen mixture confined in a soap bubble as in our experimental setup. The paper of C. Desrosier ([5]) describes a quite similar experimental investigation at reduced scale. But the detonating gas, confined in a hemispherical charge (radius $0.05 \leq R_{0} \leq 0.08 \mathrm{~m}$ ), is ignited at different locations inside the charge at ground level. The data are correlated as a function of the single parameter $\left(\lambda=\frac{R}{E^{\frac{1}{3}}}\right)$ in the range $0.5-12$.

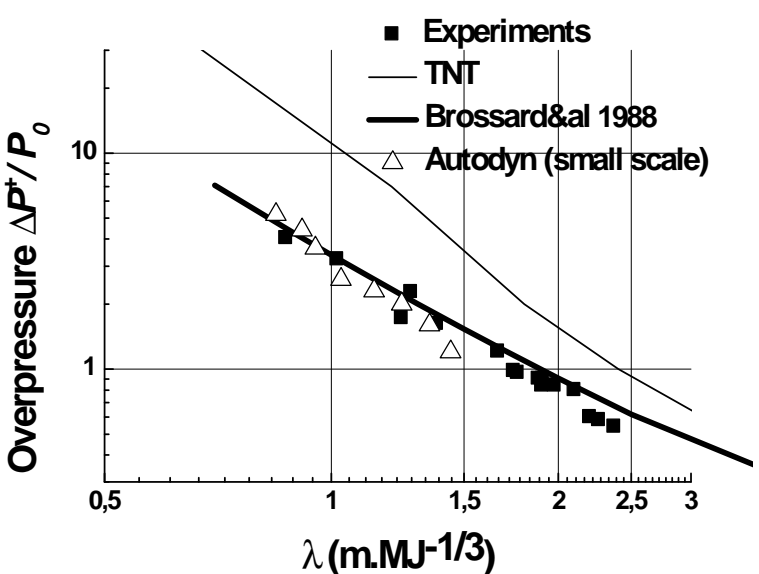

Fig. 13 Blast loadings for experimental and numerical models: positive reflected overpressure $\left(\theta_{x y}=90^{\circ}\right)$ as a function of reduced radial distance $\lambda$

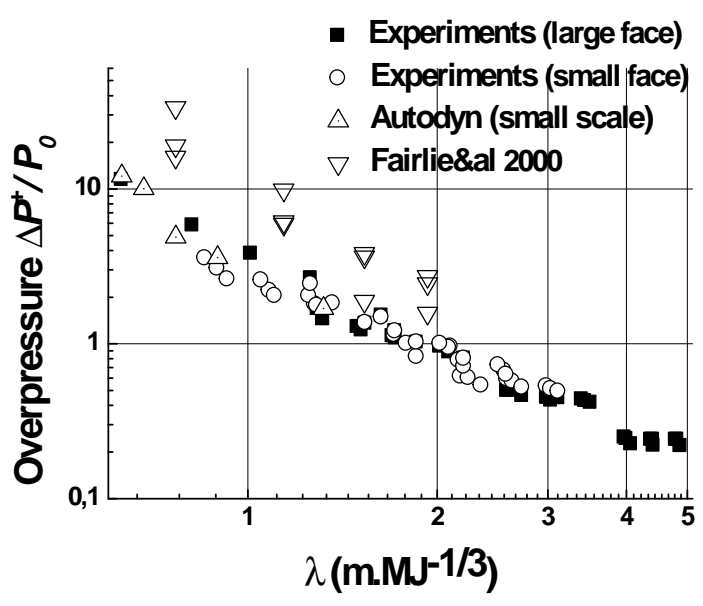

Fig. 14 Blast loadings for experimental and numerical models: positive reflected oblique overpressure $\left(\theta=45^{\circ}\right)$ as a function of reduced radial distance $\lambda$

All our experimental data are well-expressed as functions of the reduced radial distance $\lambda$ in the range $0.29-$ 4. (Fig. 11. 12. 13.). The least-squares second-order polynomials are then fit for each series of data in the case of propane-oxygen mixtures: first in the free field (incident pressures with the gauges located on the plane surface, $\left.0.29 \leq \lambda\left(\mathrm{m} . \mathrm{MJ}^{-1 / 3}\right) \leq 4.27\right)$, then for normal reflection with the configurations 1 and $2\left(0.43 \leq \lambda\left(\mathrm{m} \cdot \mathrm{MJ}^{-1 / 3}\right)\right.$ $\leq 1.97$ ), and finally oblique reflection (configuration 3 ) with $\theta=45^{\circ}\left(0.63 \leq \lambda\left(\mathrm{m} . \mathrm{MJ}^{-1 / 3}\right) \leq 4.88\right)$ (see Table 2). These results are also applicable to other gaseous mixtures ([4], [5] ) (Fig. 11. 12. 13.).

The three characteristics of the incident and reflected pressure signals are defined as follows: 


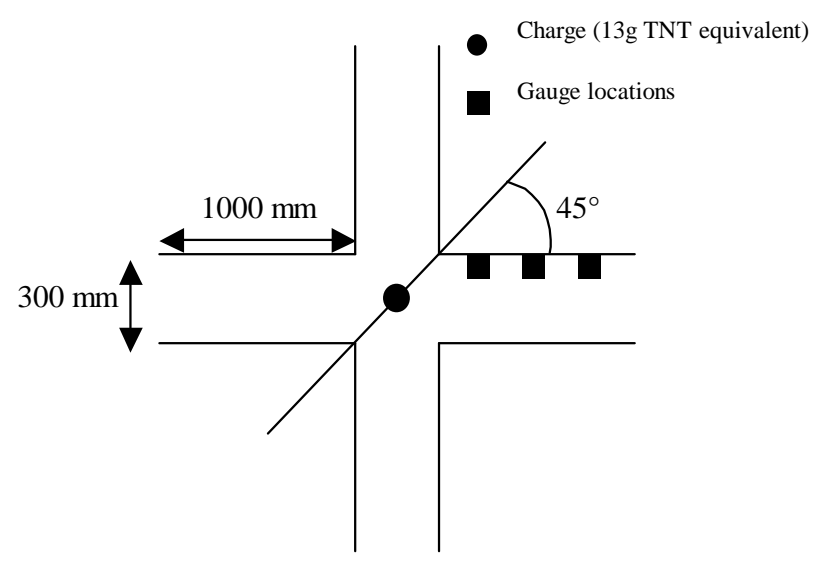

Fig. 15 Plan of Cross-Roads Small Scale Experiment Geometry $([7])$

$-\frac{\Delta P^{+}}{P_{0}}=$ peak overpressure of positive phase;

$-\frac{I^{+}}{E^{\frac{1}{3}}}=$ impulse of positive phase;

$-\frac{t^{+}}{E^{\frac{1}{3}}}=$ duration of positive phase.

Table2. Least-square polynomials of incident and reflected pressure wave characteristics versus reduced radial distance obtained for propane-oxygen mixtures.

$\ln \left(\frac{\Delta P^{+}}{P_{0}}\right)=a+b(\ln \lambda)+c(\ln \lambda)^{2}$
$\ln \left(\frac{Y^{+}}{E^{\frac{1}{3}}}\right)=A+B(\ln \lambda)+C(\ln \lambda)^{2}$
with $Y^{+}=I^{+}$or $t^{+}$

\begin{tabular}{|c|c|c|c|}
\hline & Free field & Config. 1-2 & Config. 3 \\
\hline & & & $\theta=45^{\circ}$ \\
\hline \multirow{3}{*}{$\frac{\Delta P^{+}}{P_{0}}$} & $a=0.09$ & $a=1.20$ & $a=1.14$ \\
\hline & $b=-1.76$ & $b=-2.02$ & $b=-1.91$ \\
\hline & $c=0.16$ & $c=0.18$ & $c=0.14$ \\
\hline \multirow{3}{*}{$\begin{array}{c}\frac{I^{+}}{E^{\frac{1}{3}}} \\
\text { bar.ms.MJ } J^{\frac{-1}{3}}\end{array}$} & $A=-1.19$ & $A=0.065$ & $A=-0.60$ \\
\hline & $B=-0.86$ & $B=-1.49$ & $B=-0.85$ \\
\hline & $C=0.19$ & $C=-0.11$ & $C=-0.03$ \\
\hline \multirow{3}{*}{$\begin{array}{c}\frac{t^{+}}{E^{\frac{1}{3}}} \\
m s . M J^{\frac{-1}{3}}\end{array}$} & $A=0.09$ & $A=0.12$ & $A=-0.46$ \\
\hline & $B=0.13$ & $B=0.23$ & $B=1.03$ \\
\hline & $C=0.32$ & $C=0.32$ & $C=-0.30$ \\
\hline
\end{tabular}

6 Results at ground level expressed as function of impact angle $\theta_{i}$

In this second approach, the three parameters of the blast wave generated by the detonating vapor cloud are well-correlated as functions of another parameter, $\theta_{i}=$ $\frac{\tau R_{0}}{X}\left(^{\circ}\right)$. Indeed, because of the spread of the results obtained with the correlations as function of the radial distance $\lambda$ (Fig. 16), we have decided to choose a new parameter $\theta_{i}$.

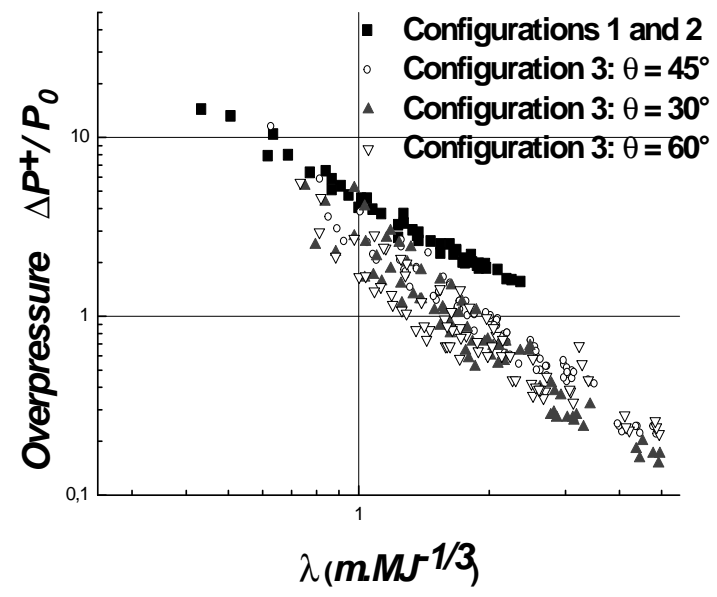

Fig. 16 Reflected positive overpressure as a function of reduced radial distance $\lambda$ (m.MJ $\left.{ }^{\frac{-1}{3}}\right)$ : oblique and normal reflection (transducers located on the structure, configurations 1,2 and 3 , fig. 4, 5 and 6 )

$R_{0}(\mathrm{~m})$ is the radius of the hemispherical gaseous charge, $\tau\left(^{\circ}\right)$ the angle formed by the gauge, the explosion source and the ground and $X(\mathrm{~m})$ the height from the ground to the gauge (Fig. 17).

As in the first approach (Section 5), the purpose is to provide the researcher with a practical and simple methodology for predicting the dynamic loads applied on the mechanical structure. In both cases, the data are correlated and fitted by least-square second-order polynomials (5) (6) and (7). Although there is still a certain spread of data obtained with this representation of overpressure, impulse and phase duration versus the impact angle, the new parameter $\theta_{i}$ presents the following advantage:

- at any point on the two faces directly exposed to the explosion,

- whatever the chemical energy release $E$,

- whatever the position of the explosion source $E s$,

the pressure history can be quantified in terms of positive overpressure, positive impulse and positive phase duration (Fig. 18. 19. 20.).

Remark 1 : from figure 17., we see that $\tan \tau=\frac{X}{r}$ with $0.03 \leq X(\mathrm{~m}) \leq 0.11$ and $r=0.10-0.15-0.20 \mathrm{~m}$ so $0.15 \leq \tan \tau \leq 1.1$ and so $8.5 \leq \tau\left({ }^{\circ}\right) \leq 47.7$. Hence, $\tan \tau$ can not be approximated by $\tau$; indeed this expression would be right if $\tau$ was very small.

$$
\begin{gathered}
\ln \left(\frac{\Delta P^{+}}{P_{0}}\right)=-2.99+1.01\left(\ln \theta_{i}\right)+0.18\left(\ln \theta_{i}\right)^{2} \\
\ln \left(\frac{I^{+}}{E^{\frac{1}{3}}}\right)=-3.35+1.10\left(\ln \theta_{i}\right)-0.02\left(\ln \theta_{i}\right)^{2}
\end{gathered}
$$




$$
\ln \left(\frac{t^{+}}{E^{\frac{1}{3}}}\right)=-0.24+0.45\left(\ln \theta_{i}\right)-0.24\left(\ln \theta_{i}\right)^{2}
$$

with $2.9 \leq \theta_{i}=\frac{\tau R_{0}}{X}\left(^{\circ}\right) \leq 33.4$

These results are located in an envelope (drawn on Fig. 18. 19. 20) which is limited by a lower limit $\mathrm{lim}^{-}$and an upper limit $\mathrm{lim}^{+}$and is defined for each characteristic as follows:

$$
\begin{aligned}
& l i m^{-}: \ln \left(\frac{\Delta P^{+}}{P_{0}}\right)=-2.84+0.45\left(\ln \theta_{i}\right)+0.28\left(\ln \theta_{i}\right)^{2} \\
& \lim ^{+}: \ln \left(\frac{\Delta P^{+}}{P_{0}}\right)=-2.91+1.37\left(\ln \theta_{i}\right)+0.12\left(\ln \theta_{i}\right)^{2} \\
& l i m^{-}: \ln \left(\frac{I^{+}}{E^{\frac{1}{3}}}\right)=-4.04+1.19\left(\ln \theta_{i}\right)-0.03\left(\ln \theta_{i}\right)^{2} \\
& l i m^{+}: \ln \left(\frac{I^{+}}{E^{\frac{1}{3}}}\right)=-3.19+1.49\left(\ln \theta_{i}\right)-0.11\left(\ln \theta_{i}\right)^{2} \\
& l i m^{-}: \ln \left(\frac{t^{+}}{E^{\frac{1}{3}}}\right)=0.38+0.69\left(\ln \theta_{i}\right)-0.28\left(\ln \theta_{i}\right)^{2} \\
& \lim ^{+}: \ln \left(\frac{t^{+}}{E^{\frac{1}{3}}}\right)=0.24+0.11\left(\ln \theta_{i}\right)-0.17\left(\ln \theta_{i}\right)^{2}
\end{aligned}
$$

with $2.9 \leq \theta_{i}\left(^{\circ}\right) \leq 33.4$

In Fig. 18., 19., 20., the Autodyn small scale points result from an Autodyn simulation conducted at the same scale as our experiments: a TNT charge of characteristic dimension $d$ and total energy $E$ is detonated at a distance $r$ from the structure (length $L$, width $l$, height $h)$. On the other hand, the Autodyn large scale points result from calculations made with Autodyn at full scale: here a TNT charge of characteristic dimension $k d$ and total energy $k^{3} E$ is detonated in the same atmosphere at a distance $k r$ from the structure (length $k L$, width $k l$, height $k h$ ).

\section{Conclusion}

In this paper, several dimensionless engineering correlations have been suggested that are expressed as a function of reduced radial distance. A new parameter has been introduced in the correlations, which includes the impact angle and distances characterizing the relative positions of the blast impact point and the explosion source.

These engineering correlations obtained at small scale experiments, allow determination of the characteristic blast loading parameters for various relative positions of the explosion charge and loaded structure.

The Autodyne code was validated against the experimental data obtained at small scale.

In summary, these results allow evaluation of the blast wave loading parameters at large scale by either using engineering correlations with Hopkinson scaling, or by simulating large scale problems directly with the validated Autodyn code.

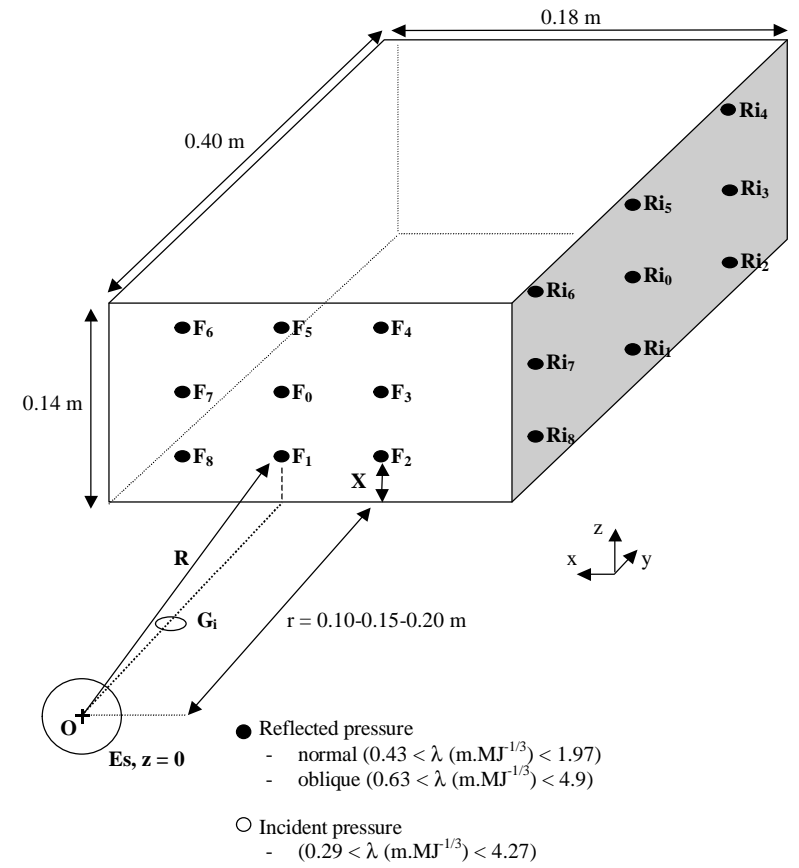

Fig. 17 Location of gauges on the parallelepipedic structure, $\theta_{x y}=0^{\circ}$ et $\theta_{z}=0^{\circ}(\mathrm{z}=0) . \mathrm{F}_{0} \mathrm{~F}_{1}=\mathrm{F}_{0} \mathrm{~F}_{5}=004 \mathrm{~m}-\mathrm{F}_{0} \mathrm{~F}_{3}=$ $\mathrm{F}_{0} \mathrm{~F}_{7}=0.06 \mathrm{~m}-\mathrm{R}_{i 0} \mathrm{R}_{i 7}=\mathrm{R}_{i 0} \mathrm{R}_{i 3}=0.17 \mathrm{~m}-\mathrm{R}_{i 0} \mathrm{R}_{i 5}=\mathrm{R}_{i 0} \mathrm{R}_{i 1}$ $=0.04 \mathrm{~m}-0.07 \leq O G_{i}(\mathrm{~m}) \leq 0.7$.

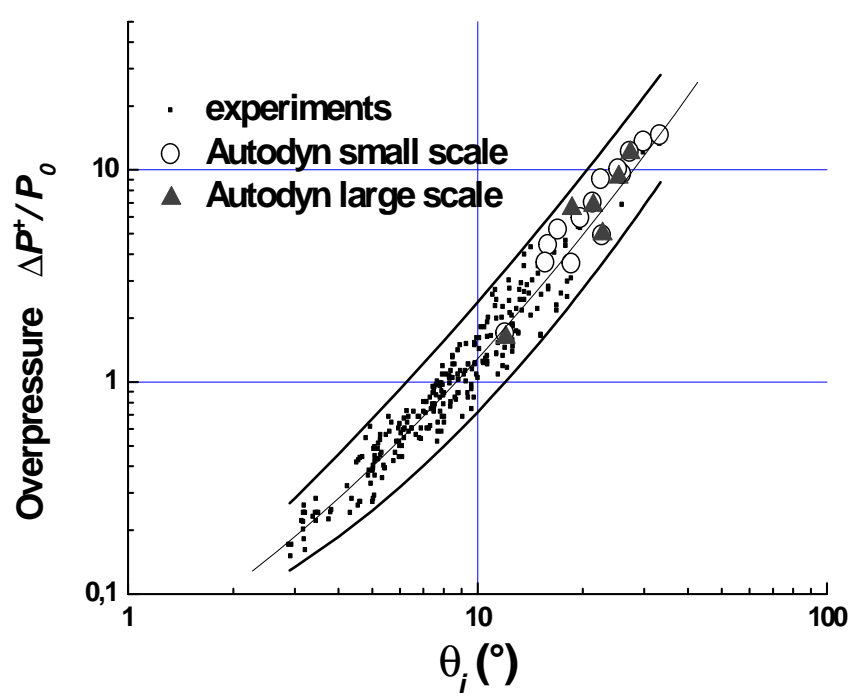

Fig. 18 Reflected and oblique overpressure versus the impact angle $\theta_{i}$ (transducers $F_{i}$ and $R_{i}$, Fig. 17). 


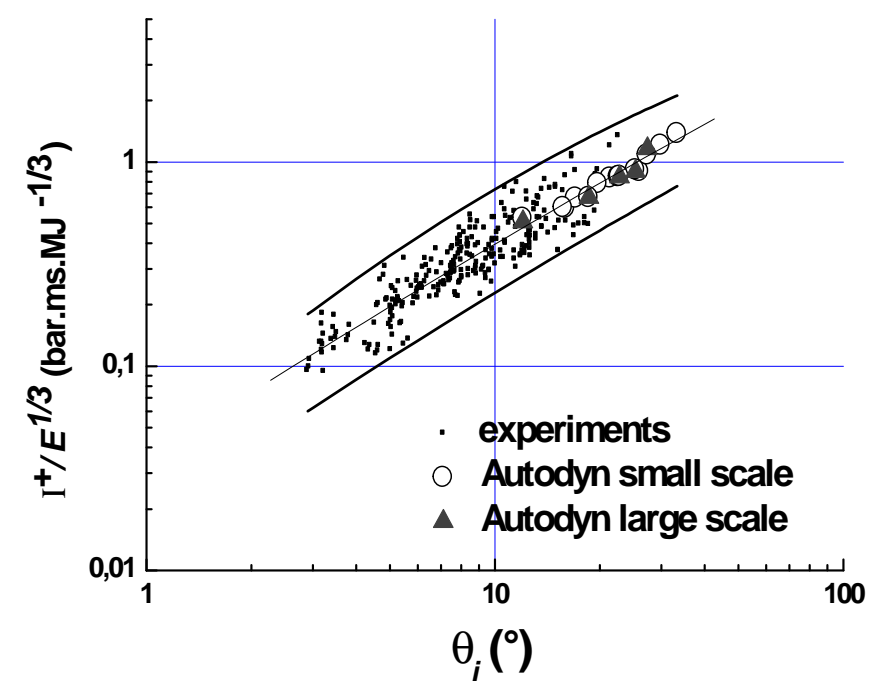

Fig. 19 Positive reflected and oblique impulse versus the impact angle $\theta_{i}$ (transducers $F_{i}$ and $R_{i}$, Fig. 17).

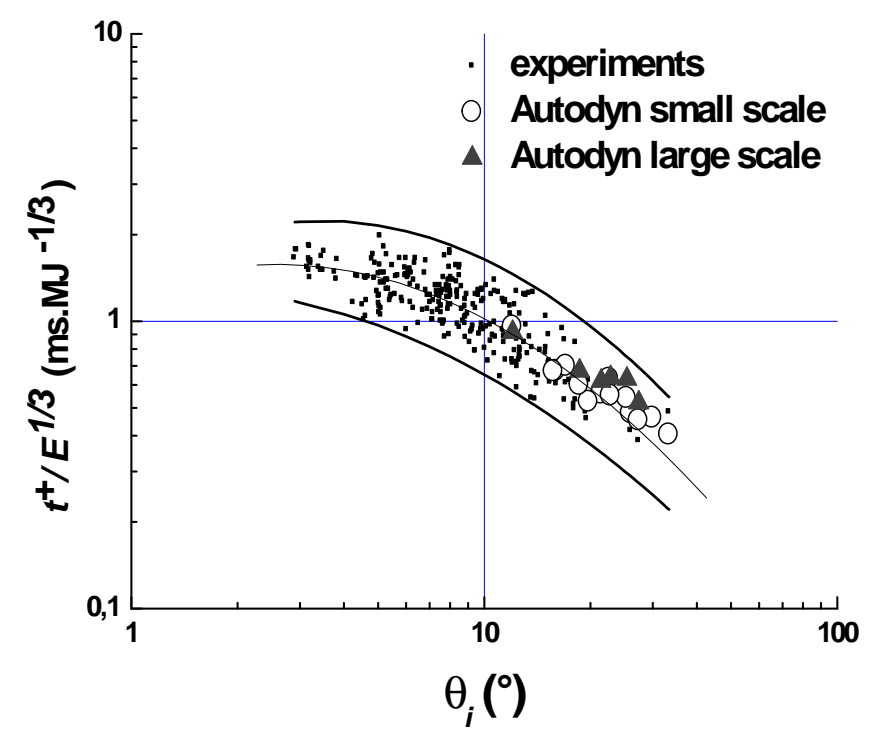

Fig. 20 Positive reflected and oblique phase duration versus the impact angle $\theta_{i}$ (transducers $F_{i}$ and $R_{i}$, Fig. 17).

Acknowledgements. We would like to thank IRSN and the European Community (Feder, FSE) for the financial support of this work, and M. Ludovic Lamoot for his help for the technical realization of the experimental setup.

\section{References}

1. Autodyn : Interactive non linear dynamics analysis software - Theory Manual - Revison 4.3 - Century Dynamics
(2003)

2. Baker W.E., Cox P.A., Westine P.S., Kulesz J.J., and Strehlow R.A.: Explosion hazards and evaluation. Fundamental Studies in Engineering. Elsevier, New-York, Elsevier (1983)

3. Brossard J., Leyer J.C., Desbordes D., Garnier J.L., Hendrickx S., Lannoy A., Perrot J. and Saint Cloud J.L.: Experimental analysis of unconfined explosions of airhydrocarbon mixtures. Characterization of the pressure field. $4^{\text {th }}$ Symposium International on Loss Prevention and Safety Promotion in the Process Industries. European Fed. of Chem. Eng. Event no. 290, D 10-19 (1983)

4. Brossard J., Bailly P., Desrosier C., Renard J.: Overpressures imposed by a blast wave. Progress in Astronautics and Aeronautics, Vol.114, pp.329-400 (1988)

5. Desrosier C., Reboux A., Brossard J.: Effect of asymmetric ignition on the vapor cloud spatial blast. Progress in Astronautics and Aeronautics, Vol. 134, pp. 21-37 (1991)

6. Dewey J.M.: TNT equivalency of explosive sources. $18^{t h}$ International Symposium on Military Aspects of Blast and Shock (2004)

7. Fairlie G.E., Johnson N.F., Moran K.C.: Validated numerical simulations of blast loads on structures. $16^{\text {th }}$ International Symposium on Military Aspects of Blast and Shock (2000)

8. Kinney G.F.: Explosive shocks in air. London, MacMillan (1962)

9. Lannoy A.: Analyse des explosions air-hydrocarbures en milieu libre: Etudes déterministe et probabiliste du scénario d'accident. Prévision des effets de suppression. Bulletin Direct. Etudes et Recherches EDF. A4 (1984)

10. TM5.1300, Departments of the Army, the Navy and the Air Force.: Structures to resist the effects of accidental explosions. Technical Manual, NAFVAC-P397 / AFM88 (1969) 